\title{
AOR
}

Selected Papers of \#AoIR2021:

The 22nd Annual Conference of the

Association of Internet Researchers

Virtual Event / 13-16 Oct 2021

\section{Rocketing sheep: Affective discipline in anonymous mobile social media Jodel during the Covid-19 pandemic}

\author{
Salla-Maaria Laaksonen \\ University of Helsinki \\ Anna Rantasila \\ Tampere University

\section{Introduction}

The Covid-19 pandemic has sparked online discussion in unprecedented volumes, as citizens use social media to share their opinions and concerns regarding the virus and its prevention. Much of such activity takes place under real names on popular platforms like Facebook and Twitter. However, parallel to these platforms more anonymous, low-visibility spaces remain and flourish, including completely anonymous services such as Secret.ly and Ask.fm, or pseudonymized services such as Reddit (Boccia Arieri et al., 2021). This study focuses on Covid-19 related discussions on anonymous, ephemeral mobile social media platform Jodel. Jodel is an anonymous-by-design application that allows messaging with others who are geographically close. There are no usernames, only running numbers that identify participants within each thread. In Finland, the application has been particularly popular among young adults and students. In this study, we explore discussions about the Covid-19 pandemic on Jodel in Helsinki, Finland through the theoretical notion of affective discipline.

By exploring the dynamics of an anonymous social media application in the context of the Covid-19 pandemic, this study contributes new insights on anonymous and ephemeral civic engagement and how affect and emotions are key in understanding the dynamics of how citizens come together in these contemporary, networked platforms (e.g., Boccia Artier et al., 2021; Papacharissi, 2015). Because the Covid-19 pandemic introduced tight restrictions on people's lives, the anonymous discussions on Jodel provide a view to how individuals cope with and discuss measures that ultimately infringe on their independence.

We approach the anonymous Jodel discussions through the concept of affective discipline (Rantasila, 2020a), which parallels how the discussions on Covid-19

Suggested Citation (APA): Laaksonen, S-M. \& Rantasila, A. (2021, October). Rocketing sheep: Affective discipline in anonymous mobile social media Jodel during the Covid-19 pandemic. Paper presented at AolR 2021: The 22nd Annual Conference of the Association of Internet Researchers. Virtual Event: AolR. Retrieved from http://spir.aoir.org. 
restrictions and preventive measures revolve around questions of control. Affective discipline refers to a set of dynamics and practices used in attempts to manage the affective intensities of public conversations (Rantasila, 2020b). While calls for restrictions by public health officials are a recognizable example of affective discipline, acts of affective discipline also take place on social media (Rantasila, 2020b). In addition to direct expressions, affective disciplining takes more subtle and vernacular forms (Das, 2017; Rantasila, 2020b), such as the use of emojis and gifs (Tuters et al., 2020).

\section{Methodology}

Our data is collected during a virtual ethnography on the @corona channel in Jodel in Helsinki 2020-21. A password-protected, hidden Tumblr blog was used for field notes, screenshots, and links. The most intensive stage of data collection was between Nov 30 and Dec 30, 2020, marked by the beginning of the second wave of the pandemic. Screenshots and field notes were also added periodically after the initial field period. This resulted in a dataset of 345 commented screenshots.

For the analysis, all posts were exported to a tabular file and processed in a spreadsheet program. The data was analysed using a data-driven approach focusing on the field notes and images combined with a qualitative content analysis of the screen-captured conversations. Our main interest was in the targets and dynamics of affective expression: How the users seek to influence the affective intensities of the anonymous discussions, in context of the pandemic in their everyday? How does Jodel's anonymous platform support these affective expressions?

\section{Preliminary Results}

The discussions were a mix of collectively processing the pandemic everyday, bemoaning other citizens' behavior, anxiously following the course of the epidemic, and collective aspirations about the post-corona future. The majority of the active users seemed to support strict restriction measures. They took the government recommendations seriously and were seemingly concerned about the virus. One motivation for the discussions seemed to be sharing news and information. In addition to this informational function, the discussions seeped in affect and emotion. Sometimes the discussion featured a peculiar mix of joy and fear, perhaps as a mechanism of coping and handling the crisis. For example, as the second wave started in Finland, the channel community started to follow and speculate the daily case numbers.

Paradoxically and ironically, the commenters anticipated the "rocket launch", that is, a steep rise of cases.

We identified several forms of affective discipline taking place on the channel. First, the discussants seeked to discipline their own affective stances. Commenters used the channel to seek advice when potentially infected, when making decisions on actions that risked spreading the virus, and shared their anxiety while waiting for test results. Further, jodlers communicated a sense of security through details and numbers, in particular through the intense following of the infection numbers. A second prevalent form of discipline was disciplining absent others-strangers, relatives, friends-by 
stalking and moralistically evaluating their actions from mask use to misinformation. In particular, discussions about restriction breakers, such as those having parties, became sites of intensive affective disciplining (cf. Ahmed, 2004; Paasonen, 2015). Further, we also observed technologically-afforded forms of disciplining (present) others: disciplining opinions in the conversation with up/downvotes, and disciplining opinions and affect by posting normative polls.

The affective discipline in the community thus culminates in moralistic judgements and reinforcing of social norms-accompanied with peer support. The enforced anonymity of Jodel supports these both, and effectively brings out the everyday concerns, affects and opinions during the pandemic. While the discussions contain moral judgements (Haidt, 2012), they were also rife with humor, irony and distanced spectatorship of the ongoing pandemic, resonating with the carnivalistic discussion cultures of other anonymous and pseudonymous platforms (Graham, 2019; Tuters \& Hagen, 2020). During our research period, the channel gained a reputation as a home for restriction bigotry. This invited opponents and trolls to join in an apparent attempt to disrupt the affective disciplining. The most upfront forms of criticism described the core posters as "corona sheep" who were bindly and uncritically following the government rules.

To conclude, we suggest that disciplining affect and emotions are key in understanding the dynamics of anonymous online communities. Despite the anonymity of Jodel, a sense of community is constituted through the practices of affective disciplining. We argue that anonymous and ephemeral platforms such as Jodel, where identities and histories are nonexistent, effectively bring out the affective forces that assemble and disassemble communities.

\section{References}

Ahmed, S. (2004). The Cultural Politics of Emotion. Edinburgh University Press

Boccia Artieri, G., Brilli, S., \& Zurovac, E. (2021). Below the Radar: Private Groups, Locked Platforms, and Ephemeral Content-Introduction to the Special Issue. Social Media + Society, 7(1), DOI:10.1177/2056305121988930

Das, R. (2017). The mediation of childbirth: 'Joyful' birthing and strategies of silencing on a Facebook discussion group. European Journal of Cultural Studies, DOI: $10.1177 / 1367549417722094$

Graham, E. (2019). Boundary maintenance and the origins of trolling. New Media and Society 21(9), DOI:10.1177/1461444819837561

Haidt, J. (2012). The Righteous Mind: Why Good People are Divided by Politics and Religion. Penguin.

Paasonen, S. (2015). A midsummer's bonfire: Affective intensities of online debate. In Hillis K., Paasonen S. \& Petit M (Eds.) Networked affect (pp. 27-42). MIT Press. 
Papacharissi, Z. (2015). Affective Publics. Sentiment, Technology, and Politics. Oxford University Press.

Rantasila, A. (2020a). Circulating Emotions, Sticky Feelings. Affective Dynamics of the Fukushima Daiichi Nuclear Disaster in a Hybrid Media Environment. Doctoral dissertation, Tampere University. http://urn.fi/URN:ISBN:978-952-03-1764-5

Rantasila, A. (2020b). Managing Unpleasant Moods. Affective Discipline in Facebook Discussions. European Journal of Cultural Studies, DOI: 10.1177/1367549420973217

Tuters, M., \& Hagen, S. (2020). (((They))) rule: Memetic antagonism and nebulous othering on 4chan. New Media \& Society, 22(12), 2218-2237.

DOI: $10.1177 / 1461444819888746$ 